\title{
El riesgo inherente al proveedor como criterio preventivo en la contratación pública***
}

\section{The Inherent Risk of the Supplier as a Preventative Criterion in Public Procurement}

RESUMEN

El manejo del riesgo de incumplimiento atribuible a las características de los proveedores en la contratación pública en Colombia se limita a la exigencia de garantías, medidas contractuales de presión o la implementación de cláusulas exorbitantes al derecho común. En tal sentido, el Estado colombiano carece de una metodología para monitorear el riesgo que los proveedores acumulan con el tiempo y el riesgo que les es sobreviniente por circunstancias técnicas, financieras o de mercado; de ahí que no cuente con un registro de información parametrizada para clasificar a los contratistas acorde con su historial de desempeño, calidad y proclividad al incumplimiento contractual. Ante lo dicho, el Estado no cuenta con suficientes medidas previas de mitigación para contrarrestar los efectos nocivos derivados de un reconocido "mal prestador" o de un contratista con potencial de riesgo de incumplimiento medio o alto. Por el contrario, las garantías y exigencias requeridas durante el proceso de selección aplican de igual forma para todos los interesados, sin que haya diferenciación frente a quienes presenten un historial de incumplimientos,

* Abogado de la Universidad Externado de Colombia. Candidato a LL.M. (Masters of Law) en International Dispute Resolution en King's College London. Magíster en Gobierno y Políticas Públicas de la Universidad Externado de Colombia. Profesor del Departamento de Derecho Constitucional de la Universidad Externado de Colombia. Contacto: juan.charris@ uexternado.edu.co

** Comunicador Social y Periodista de la Universidad de la Sabana. Magíster en Gobierno y Políticas Públicas de la Universidad Externado de Colombia; especialista en Contratación Estatal de la Universidad Externado de Colombia; especialista en Gerencia Estratégica de la Universidad de la Sabana; posgraduado en Planeación Urbana de la Pittsburgh University. Contacto: gerencia. 1lamas@gmail.com

*** Recibido el 11 de junio de 2016, aprobado el 1. . de octubre de 2016.

Para citar el artículo: J. P. Charris Benedetti y A. C. Llamas Foliaco. El riesgo inherente al proveedor como criterio preventivo en la contratación pública. Derecho del Estado n. ${ }^{\circ} 37$, Universidad Externado de Colombia, julio-diciembre de 2016, pp. 95-125. Dor: http://dx.doi. org/10.18601/01229893.n37.03 
multas y/o sanciones, entre otras especificaciones de riesgo. El presente escrito plantea la necesidad de asimilar el concepto de riesgo inherente al proveedor como criterio objetivo y estandarizado, desde una perspectiva preventiva más que correctiva, de tal suerte que el Estado pueda mejorar la efectividad de sus contratos públicos y disminuir la materialización de los efectos negativos derivados de la contratación fallida.

\section{PALABRAS CLAVE}

Contratación pública, riesgo del proveedor, mitigación del riesgo, evaluación de desempeño, medidas preventivas.

\section{ABSTRACT}

The risk management of non-compliance attributable to the suppliers in Colombia's public procurement is limited to the guarantees' requirements, pressures associated with contractual measures, or the Public Administration's exceptional clauses. In this regard, the Colombian State lacks a methodology to monitor the performance of contractors and the risk they accumulate over time, as well as the risk that they are supervening due to technical, financial or market conditions; hence there is no record of parameterised data to classify contractors according to their performance, quality and tendency to breach the contract. Given the above, the State does not have prior measures of risk mitigation to counteract the harmful effects arising from a recognised 'bad provider' or a contractor with medium or high risk potential to breach the contract. By contrast, the guarantees and requirements demanded during the selection process apply equally to all applicants without any differentiation for those with a history of non-compliance, fines or penalties, among other risk specifications. This paper raises the need to assimilate the concept of inherent risk in the supplier as an objective and standardised criterion, from a preventative rather than corrective perspective, in such a way that the State can improve the effectiveness of their public contracts and reduce the negative outcomes resulting from failed contracting.

KEYWORDS

Public procurement, risk of the supplier, risk mitigation, performance assessment, preventive measures.

SUMARIO

Introducción. I. Aspectos para la clasificación de riesgo inherente al proveedor. II. El Registro Único de Proponentes y el riesgo inherente al proveedor. III. 
Medidas para contrarrestar la ocurrencia de hechos que perturben la ejecución contractual imputable al contratista. IV. Medidas legales adoptadas por el sistema actual para identificar a los prestadores que representan riesgo para la contratación estatal. v. El caso Ecopetrol en Colombia: estudio del historial de desempeño contractual para la selección de contratistas. VI. Modelos internacionales de evaluación del desempeño para mitigar el riesgo inherente al proveedor. Conclusiones. Referencias.

\section{INTRODUCCIÓN}

La contratación pública en Colombia confiere un manejo limitado al riesgo de incumplimiento por circunstancias que rodean a los proponentes (futuros contratistas) de bienes y servicios del Estado. Para mitigar el riesgo inherente al proveedor, el enfoque se restringe exclusivamente a lo correctivo, ya sea con la exigencia de garantías contractuales (como pólizas de seguros) tendientes a que se ejecute o termine de ejecutar la obra por parte del garante cuando un prestador negligente incumplió; o con el recurso a medidas contractuales de presión (como las cláusulas penales, las multas, los descuentos y las glosas), diseñadas para conminar al contratista a cumplir sus compromisos contractuales; o por la aplicación de las llamadas cláusulas excepcionales y exorbitantes al derecho común (como la caducidad y las de terminación, modificación e interpretación unilateral del contrato), que funcionan como medidas de choque al amparo de las prerrogativas de la Administración Pública.

Partiendo de la base de que es más difícil mitigar en ejercicio lo que era reducible antes de la celebración del contrato, resulta pertinente examinar el escenario de eventuales incumplimientos del contratista con anterioridad al inicio de la relación contractual. Ahora, ¿por qué con anterioridad? En primer término, por cuanto a un mal contratista le asiste, por derecho y al amparo del debido proceso constitucional, un catálogo de recursos y herramientas jurídicas para dilatar las medidas en su contra, aunado al papel que juegan las compañías de seguros como coadyuvantes para impedir el pago de un siniestro. Surgen entonces los siguientes interrogantes: ¿cuándo sería apropiado generar las medidas de mitigación adecuadas al riesgo inherente al proveedor, antes de la celebración del contrato o durante la relación contractual?, ¿cómo podría el Estado mitigar el riesgo proveedor antes del inicio de la relación contractual?, ¿qué medidas podría adoptar el Estado para incentivar al proveedor a observar una gestión responsable de los recursos públicos?

Por sustracción de materia, el momento idóneo para generar medidas efectivas de mitigación del riesgo inherente de un proveedor proclive a incumplir es la fase precontractual. Para lograr esta finalidad, es indispensable que el Estado conozca, no solo el comportamiento histórico de los provee- 
dores en el mercado (dilaciones de plazo, manejo de anticipos, calidad de las prestaciones, etc.), sino su caracterización situacional en general (nuevo proveedor nacional o extranjero, situación financiera en riesgo moderado $\mathrm{u}$ otro tipo de riesgo, empresa en estado de reorganización empresarial, etc.), en aras de conocer la realidad comercial del sujeto y generar medidas previas de mitigación diferenciadas, no restrictivas, acorde a su clasificación de riesgo. Ahora bien, una de las mayores limitantes para abordar el tema de las medidas de mitigación preventivas y diferenciadas frente a proveedores en la contratación estatal es que la literatura al respecto es escasa.

El riesgo inherente sería aquel que se encuentra vinculado al sujeto, por el hecho de ser quien es. Esta circunstancia es valorada por las aseguradoras en múltiples supuestos, como ante la edad de quien solicita un seguro de vida, en el caso de tener que tasar el valor del amparo contra incendios de un laboratorio que trabaja con material explosivo, o bien de decidir si otorgar o no un seguro de automóvil a un sujeto con múltiples antecedentes de accidentalidad vehicular. En esencia, existen riesgos propios del sujeto, intrínsecos a su existencia y características propias, sin perjuicio de que puedan mejorarse los indicadores de materialización de hechos graves.

Pensar en el riesgo que les es propio a los sujetos tiene especial importancia en la aplicación de recursos del Estado sobre la iniciativa privada, ya que impacta las dinámicas del mercado y variables de suma trascendencia para el desarrollo. En términos macroeconómicos, los contratistas contribuyen decididamente con la economía y poseen su propia personalidad en el contexto del mercado acorde a su historial de desempeño y la tipología contractual en la que transcurren ${ }^{1}$.

Por su parte, el Estado está llamado a comprender quiénes son sus proveedores y cómo puede motivar su actuación y competitividad, mientras que ejerce el control contractual y observa su desempeño, para minimizar el riesgo y optimizar los recurso públicos. En efecto, según anota Santofimio, "[1]o que se quiere en nuestro ordenamiento por regla general no son destinos inciertos y oscuros para el contrato del Estado, o el riesgo absoluto en los negocios públicos, sino, por el contrario, la mesura, el cuidado, la planeación suficiente, la distribución de riesgos y no el camino fácil de la asunción de responsabilidades y riesgos sin control" 2 .

No obstante, la política pública de contratación en Colombia no prevé mecanismos de prevención respecto de la reputación o tendencia de sus con-

1 Basu, K. Más allá de la mano invisible. México: FCE, 2011, 115.

2 SANTOFimio, J. O. El carácter conmutativo y por regla general sinalagmático del contrato estatal y sus efectos respecto de la previsibilidad del riego y del mantenimiento de su equilibrio económico. Revista digital de Derecho Administrativo, Universidad Externado de Colombia, n. ${ }^{\circ} 1,2009,18$. 
tratistas a materializar incumplimientos, fuera de las ya conocidas pólizas de seguros y las medidas legales de presión.

Desconocer que el Estado obtiene beneficios al observar la conducta y características de sus proveedores, o no atender a la clasificación de riesgo inherente de quienes actúan o pretenden actuar en el mercado de lo estatal, es desatender la posibilidad de construir medidas de control e incentivo para impulsar a estos actores sustanciales de la economía a que se comporten conforme a los fines esenciales del Estado. Los proveedores, desde luego, son actores de primer orden en la dinámica socioeconómica, protagonistas que impactan indicadores básicos de estabilidad, como el empleo y la demanda agregada de bienes y servicios. En este sentido, al Estado le corresponde garantizar la rentabilidad y el retorno de la inversión, lo cual en nada transgrede el ordenamiento jurídico o afecta injustificadamente el patrimonio del Estado, siempre que se conserve la orientación al beneficio público ${ }^{3}$.

Ahora, motivar la participación de los proveedores implica simultáneamente conocerlos y caracterizarlos, en particular en lo relacionado con su desempeño y situaciones de mercado. Este es el fundamento para desarrollar estrategias, acciones y medidas de mitigación preventivas, no con intenciones restrictivas que limiten su participación en el mercado, sino con el propósito de reducir la materialización de ciertos riesgos, o bien superarlos con mayor suficiencia si llegasen a concretarse. Tales circunstancias de coexistencia e interdependencia entre Estado y empresa privada agregan valor a los fines públicos y al concierto económico, a pesar de la divergencia de sus intereses.

Como advierte Benavides: "[L]os intereses principales de cada una de las partes del contrato estatal no son equivalentes. Pero la tendencia a la aproximación de las partes, así como su colaboración recíproca, obliga al mismo tiempo a que cada una tenga en cuenta el interés de la otra. Así, la administración debe garantizar los intereses del contratista, y éste ha de tener en cuenta su condición de colaborador de la administración"4.

En esencia, la reciprocidad debe orientarse al conocimiento mutuo, al control, fomento y seguimiento, respetando esa facultad dominante del Estado en sus contratos, en beneficio del bien común. La empresa privada plantea retos de conocimiento del entorno, desafíos sobre conocerse a sí mismo, adaptarse y transformarse cuando las circunstancias del mercado lo requieran; de ahí la importancia de que el Estado conozca la conducta y las características asociadas al riesgo intrínseco de los proveedores en el mercado, es decir, que entienda cómo responden a los desafíos, exigencias,

3 Mierr Barrosa, P. Los riesgos, su identificación, asignación y amortización en los contratos del Estado. En Revista de Ingeniería, Universidad de los Andes, n. 32 (julio-diciembre), 2010,100 .

4 Benavides, J. L. El contrato estatal. Bogotá: Universidad Externado de Colombia, $2004,143$. 
competencia, capacidad financiera, mejoramiento tecnológico; cómo trabajan y cuál es su motivación comercial.

Si entendemos la contratación pública como un mecanismo de intervención fundamental de la política económica y social, la contratación fallida -atribuible a la trayectoria de un sujeto-, lejos de contribuir con dichos fines, los deprime. Al tenor de lo señalado por Suárez Beltrán:

Es este sin duda uno de los objetivos más ambiciosos de la reforma, al permitir que, dentro de las circunstancias que enmarca la ley con los parámetros que posteriormente desarrolle el reglamento, pueda el Gobierno Nacional enfocar su poder de compra como instrumento de intervención en el mercado, buscando resultados en términos de política económica y social. Si se considera que entre nosotros el tamaño de la contratación pública superaría el 11\% del PIB según Conpes, el efecto de esta medida puede ser significativo ${ }^{5}$.

En la actualidad el Estado colombiano no cuenta con una metodología específica en su normativa (Estatuto General de Contratación de la Administración Pública y sus respectivos reglamentos) ni en su política pública de compras y adquisiciones estatales para evaluar o clasificar el riesgo que acumulan o adquieren sus proveedores en el tiempo, ya sea por los impases en el desempeño en contratos anteriores, o bien por circunstancias de mercado que los afectan, para lograr prevenir efectivamente los efectos socioeconómicos adversos de la contratación fallida.

Creemos que el conocimiento del mercado en el marco del deber del Estado en la economía nacional se logra con información centralizada, homogénea y confiable para hacer los análisis que permitan una inversión pública menos riesgosa y más objetiva. Ahora, si bien se dispone de un sistema de información unificado en el Registro Único de Proponentes, este se queda corto al no permitir valorar, por ejemplo, la clasificación de riesgo inherente de un empresario extranjero, que por el solo hecho de ser nuevo en la contratación de un país está sujeto a dificultades contractuales que el Estado puede mitigar. En contraste, es común encontrar empresas privadas o públicas de régimen industrial y comercial con sistemas de evaluación de desempeño para contratistas, y con un catálogo de medidas puntuales para mitigar o evitar completamente el riesgo proveedor, tendientes a generar información y que la utilizan para construir parámetros de prevención.

5 SuÁrez Beltran, G. La nueva contratación pública en Colombia. Anotaciones sobre la Ley 1150 de 2007 y sus decretos reglamentarios. Bogotá: Legis, 2009, 106. 


\section{ASPECTOS PARA LA CLASIFICACIÓN DE RIESGO \\ INHERENTE AL PROVEEDOR}

Los riesgos inherentes al proveedor pueden ser tomados de información que arroja el mercado, a partir de las estadísticas que producen las entidades que concentran información de la contratación estatal. Entre tanto, se detectan incumplimientos contractuales frecuentes de empresas con poca trayectoria en el mercado. Así mismo, es usual ver empresas extranjeras que llegan a contratar con el Estado colombiano habiendo tenido buen desempeño en sus países de origen pero incumplen o incurren en malas prácticas en Colombia. Es decir, existen situaciones de facto para iniciar una clasificación de niveles de riesgo por circunstancias meramente situacionales, fuera de aquellas que tienen que ver con la trayectoria de las empresas.

Existen múltiples evidencias que ayudan a identificar riesgos asociados a ciertas características: desempeño histórico, circunstancias concretas de los potenciales contratistas, entre otros, que permiten deducir un proceder proclive a incurrir en fallas o incumplimientos, es decir, con cierto grado de riesgo contractual. Como se mencionó, clasificar ese riesgo en las dimensiones adecuadas de tipo jurídico, técnico, financiero y de mercado (bajo, medio, medio alto, alto) es el verdadero desafío práctico para conducir a la adopción de medidas objetivas y diferenciadas, orientadas a prevenir los eventos indeseables o mitigar el riesgo de mejor manera ${ }^{6}$.

Bajo el ideal de contar con un acervo significativo de información consignada en el Registro Único de Proponentes (RUP), que contenga o permita elaborar una clasificación de riesgo inherente al proponente, sea por su desempeño o por circunstancias de mercado (distinto a lo que incluye el proveedor -a su arbitrio- en sus formatos de registro), puede construirse una serie objetiva de medidas preventivas y diferenciales de aplicación a los proponentes, claro está, al amparo normativo.

Aunque el Estado colombiano ha precisado la necesidad de conocer los sectores del mercado en los que interviene, como una necesidad indiscutible para una mejor práctica contractual ${ }^{7}$, al parecer las preocupaciones se han enfocado mayormente en los precios, en los ofrecimientos (portafolios), en las características generales y en algunas calificaciones financieras de los actores de mercado. Esta línea ha sido desarrollada de forma general por Colombia Compra Eficiente a través de guías, sin que el recaudo de información confiable respecto de la trayectoria o circunstancias particulares de las empresas sea materia de análisis. Al respecto, Suárez Beltrán considera:

6 Véase Gobierno de Colombia, Colombia Compra Eficiente. En Guía de garantías en procesos de Contratación.

7 Véase Gobierno de Colombia, Colombia Compra Eficiente. En Guía para la Elaboración de Estudios de Sector. 
Debe a esta altura comentarse que, aunque el artículo 20 del decreto 1510 de 2013 no incluyó el análisis del sector, dentro de los elementos mínimos que deben contener los estudios previos, es evidente que allí sí deben constar. En ese sentido, recuérdese que el artículo 15 del decreto obliga a las entidades a [...] hacer el análisis económico necesario para conocer el sector relativo al proceso de contratación [...] y ordena dejar constancia del análisis en los documentos del proceso. Ciertamente tal "constancia" debe entonces quedar consignada como parte de los estudios y documentos previos. Sobre cómo deba realizarse ese estudio de mercado, deberá estarse atento a las instrucciones que sobre el particular imparta Colombia Compra Eficiente, las que desde luego serán indicativas y será la entidad quien deba perfilar el documento respectivo según sus necesidades ${ }^{8}$.

Lo anterior podría derivar en un mero formalismo, puesto que dejar una tarea tan enorme y técnica, como lo son los estudios de sector, para que sea implementada individualmente por todas y cada una de las entidades públicas que en Colombia compran, es un reto de proporciones astronómicas. Si las entidades públicas en Colombia, aparte de los lineamientos que puedan ser obtenidos de los manuales de Colombia Compra Eficiente, no cuentan con estudios especializados válidos a nivel nacional y regional, la construcción de semejantes estudios es claramente una utopía. No es un secreto que las guías para estudios de sector suelen ser diligenciadas con toda clase de información irrelevante, desactualizada, descontextualizada y extraída de internet, sólo para cumplir requisitos. Finalmente, es frecuente observar que la información obtenida no sea técnicamente la base para sustentar los requisitos jurídicos, técnicos y financieros en los pliegos de condiciones. En todo caso, en lo desarrollado en las mencionadas guías no existe referencia para abordar el asunto del riesgo inherente al proveedor ${ }^{9}$.

A partir de lo expuesto cabe hacer referencia a medidas concretas sobre el rango de clasificación de riesgo inherente al proveedor, antes de la suscripción del contrato. Sumado a la ventaja preventiva, una herramienta que permita identificar la clasificación de riesgo de los proponentes les forzaría a controlar variables de supervivencia y competitividad en el mercado de lo público. Muy seguramente perseguirían mantenerse en bajos niveles de riesgo ligado a su nombre comercial, con ventajas asociadas a los costos de suscripción del contrato (garantías u otras exigencias a lugar) acorde a la situación de riesgo particular de cada cual.

8 SuÁrez Beltran, G. Estudios de Derecho Contractual Público. Bogotá: Legis, 2009, 4.

9 Véase Gobierno de Colombia, Colombia Compra Eficiente. En Manual para la identificación y cobertura del riesgo en los procesos de contratación. 
II. EL REGISTRO ÚNICO DE PROPONENTES Y EL RIESGO

INHERENTE AL PROVEEDOR

Hoy en día las entidades públicas tienen la obligación legal de remitir la información de multas y/o sanciones a las cámaras de comercio para constancia en el Rup. Esta dinámica no incluye variables de riesgo previo a la materialización de los incumplimientos, que, en determinados periodos de tiempo, permite describir una curva de comportamiento o tendencia a la materialización de ciertos hechos o comportamientos de los proveedores. En todo caso, la información de multas y sanciones, aunque válida y útil, resulta insuficiente para tomar medidas preventivas, esto por cuanto el daño ya está ocasionado. Lo anterior porque, aun si la garantía sale a rescatar la situación, en el siniestro siempre subyacen perjuicios morales que no alcanzan siquiera a cuantificarse, así como particularidades socioeconómicas de aquellas que por definición confieren algún grado de deber jurídico en materia de prevención al Estado ${ }^{10}$.

Pero hay algo aún más determinante, a saber, que los hechos reportados al RUP como ya acaecidos no vienen acompañados de indicaciones normativas para que las entidades públicas adopten medidas de mitigación del riesgo inherente de ese proveedor, a menos que ya se encuentra incurso en inhabilidades e incompatibilidades. Este asunto es particularmente grave pues hay que dejar participar al incumplido en igualdad de condiciones con los cumplidos, cuando no son en lo absoluto iguales. Si se toma como base el análisis de riesgo que emplea una compañía de seguros, por ejemplo, para asignar una póliza de vehículo a un particular, es notable que, en la medida en que el historial del solicitante reporte altos índices de accidentalidad, la compañía modificará el valor del seguro, si es que acepta otorgarlo. Y el propio Estado suele determinar acciones preventivas frente a conductores alicorados, tal como la suspensión temporal de la licencia, más la imposición de multas diferenciales según el grado de alcoholemia establecido.

En este sentido, si el Estado registrara en el Rup la información del desempeño y características generales de los contratistas, podría acoger medidas objetivas de mitigación. Cuando hacemos énfasis en características generales no hablamos de asuntos de poca relevancia, sino de temas de la importancia que tienen, por ejemplo, el incremento sustancial del índice de endeudamiento de un año a otro, el hecho de tratarse de una empresa en medida de reestructuración empresarial, el que el proveedor cuente con menos de un año en el mercado, el que la empresa multinacional sea nueva en Colombia, el que la compañía esté enfrentando un litigio societario.

10 Bernal Perdomo, J. y Molina Betancur C. En Derecho administrativo. Bogotá: Legis, 2016,510 . 
No se trata solo del historial de inconvenientes o incumplimientos, sino de factores objetivos que puedan llevar a un contratista a incumplir un contrato. Así, pueden existir otras múltiples circunstancias que es oportuno valorar respecto de un proveedor: contaminación del medio ambiente, condenas por demandas laborales de sus trabajadores, incumplimiento de obligaciones laborales, alta accidentalidad en contratos anteriores y, desde luego, todo lo relacionado con las obligaciones contractuales (tiempos de entrega, calidad de los productos y servicios, personal acorde a lo solicitado, entre otros). Lo anterior afecta directamente la ejecución de los contratos y no necesariamente se resuelve vía multas y/o sanciones debidamente ejecutoriadas. Se pueden contabilizar inconvenientes recurrentes que otorgan información relevante sobre el comportamiento de un prestador. Para registrar el resumen de los mencionados aspectos, nada mejor que el RuP. Por supuesto, cada tema y aspecto requiere su valoración y su clasificación, así como sus medidas de mitigación.

Con cierto grado de asertividad, se ha manifestado que el RUP, no obstante disponer de la plataforma para convertirse en una herramienta vital para el conocimiento del mercado por parte del Estado, todavía no aporta el suficiente valor agregado a la contratación pública en Colombia.

Tal insuficiencia es señalada por Suárez Beltrán: “A la situación descrita se llegó, entre otras razones, porque el Registro Único de Proponentes creado en la Ley 80 de 1993 no cumplía la función de ser plena prueba de las circunstancias del proponente que en él deben constar, como quiera que aquella no les confirió a las cámaras de comercio la facultad de verificar la información aportada por el proponente" ${ }^{11}$.

En igual sentido, advierte Safar Díaz: "Bajo la legislación actual, este registro [refiriéndose al RUP] cumple una función puramente informativa, dado que la calificación de los factores que se denominan de verificación de cumplimiento y la clasificación en las diferentes actividades económicas es efectuada por el interesado en contratar con el Estado y no deriva de unos parámetros de evaluación previamente definidos de conformidad con las necesidades mínimas de la administración" 12 .

Efectivamente, el RuP no cumplía la función de ser plena prueba de las circunstancias del proponente. Ahora bien, aunque se estime que tal situación quedó subsanada con la adopción de la Ley 1150 de 2007, en la práctica falta mucho para que el registro arroje información relevante sobre los contratistas del Estado en los mercados y se convierta en plena prueba de

11 SuÁrez Beltrán, G. La nueva contratación pública en Colombia. Anotaciones sobre la Ley 1150 de 2007 y sus decretos reglamentarios. Bogotá: Legis, 2009, 61.

12 SAFAR Díaz, M.,Análisis económico de los procedimientos de selección de contratistas del Estado en el Derecho colombiano: hacia un mecanismos eficiente y transparente. Serie de Derecho Administrativo n. ${ }^{\circ}$ 6. Bogotá: Universidad Externado de Colombia, 2009, 71. 
las circunstancias de los proponentes. Hay que agregar que la cobertura del mismo sigue circunscrita al ámbito del Estatuto General de Contratación de la Administración Pública, y que solo recibe de las entidades públicas la información relativa a las multas y/o sanciones ejecutoriadas. Se trata de un conocimiento escaso y que solo permite saber algo sobre el riesgo proveedor cuando ya existen hechos consumados.

Se espera, igualmente, que el reporte de información sobre los contratos de las entidades públicas en Colombia sea ciertamente universal; en otras palabras, que no se limite solo a entidades regidas por el Estatuto General de Contratación de la Administración Pública, sino que abarque un mayor espectro de entidades cobijadas en regímenes especiales y excepcionales. De tal manera, se cubriría un mayor volumen de información de mercado que hasta el momento permanece en terreno desconocido.

No pretendemos sugerir que todas las entidades públicas deban sujetarse al Estatuto General de la Administración Pública; se estima, más bien, que, con independencia del régimen jurídico para contratar (exceptuado o no), ha de ser obligatorio el reporte del comportamiento de los contratistas en todos los contratos estatales en el Rup de las cámaras de comercio. Lo anterior, sin que la Ley 80 de 1993 tenga injerencia alguna en los tiempos e instancias que, por manuales internos de contratación y leyes especiales, cobijen a ciertas entidades exceptuadas. Es decir, no se trata de sometimiento al Estatuto, sino de espacios universales de información y publicidad. Así como los de apostar por la transparencia, los beneficios de conocer el mercado son sustanciales.

Adicionalmente, el reporte debe ser centralizado, de tal manera que se facilite la efectiva recolección de la información, la fácil consulta por los interesados y un deber y control de actualización permanente. Así lo propone Safar Díaz:

[S]e sugiere que la función de clasificación sea trasladada a las cámaras de comercio o a cualquier otro órgano con la capacidad suficiente para realizar esta tarea, con el fin de conformar un listado único del que todos los entes públicos que tienen capacidad para celebrar contratos estatales puedan obtener la información que requieren sobre los proponentes debidamente depurada y actualizada, de tal manera que pueda abrirse un procedimiento simple de inscripción de los proponenes en las entidades públicas con las que quieran contratar, y que éstas realicen una valoración ponderable de las capacidades de cada oferente en cada contratación específica ${ }^{13}$.

Vale mencionar que algunas entidades del Estado -por su cuenta y normalmente bajo regímenes excepcionales de contratación- tienen registros de proveedores para consignar información de sus contratistas, constituyendo 
fuentes útiles para la toma de decisiones. Estos mecanismos, sin embargo, son escasos y no hacen parte de una política pública de compras estatales consolidada. Se trata de casos excepcionales, que trataremos más adelante.

III. MEDIDAS PARA CONTRARRESTAR LA OCURRENCIA DE HECHOS

QUE PERTURBEN LA EJECUCIÓN CONTRACTUAL IMPUTABLE

AL CONTRATISTA

En la actualidad los amparos, que constituyen la garantía contractual invocada en los pliegos de condiciones, son solicitados bajo los mismos parámetros para todos los participantes en un proceso de selección, independientemente de que alguno de los proponentes represente mayor o menor riesgo al incumplimiento. A primera vista tal interpretación parece lógica a la luz del principio de igualdad en la función administrativa ${ }^{14}$, consagrado en el artículo 209 CP.

La pregunta, evidente para las compañías de seguros, es la siguiente: ¿son equiparables dos sujetos de los cuales uno de ellos presenta alta siniestralidad y el otro baja o nula? No tiene discusión, las aseguradoras diferencian estas circunstancias y sus decisiones van dirigidas a la protección de su patrimonio, aun cuando determinen otorgar la póliza. Quien no lo ha contemplado como parámetro de observación es el Estado, quien tiene a su cargo el patrimonio público y el bienestar social.

Consideramos que el Estado no ha observado el asunto de la siniestralidad para modular los amparos y coberturas según el riesgo atribuible a los proveedores porque sobre el particular no existen desarrollos teóricos en el derecho administrativo, al menos en Colombia. La garantía contractual se destina, entre otras cosas, a amparar toda suerte de incumplimientos del contratista, e incluso asuntos de responsabilidad civil extracontractual, pero el criterio de asignar parámetros diferenciados acorde al riesgo según si el proveedor es proclive a incumplir o presenta un índice bajos o nulo de incumplimiento es un área desconocida en el ámbito estatal. Conforme a lo anterior, estimamos que es lógico que las entidades públicas puedan y deban adoptar medidas diferenciadas de mitigación precontractual frente a proponentes cuyo riesgo de incumplimiento sea diferente.

Adicionalmente, la configuración de las garantías a solicitar a los proponentes en los pliegos de condiciones de la contratación pública en Colombia merece mayor precisión y desarrollo. Es preocupante que los porcentajes de

14 En Sentencia T-731 de 1998, la Corte Constitucional explicó que el principio de igualdad en la función administrativa "implica la exigencia constitucional de que la gestión de la Administración Pública no establezca distinciones injustificadas entre los administrados y obre respecto de ellos y de sus intereses guardando equilibrio, de modo que garantice a todos, en condiciones adecuadas a sus circunstancias, el acceso a ella y a sus funcionarios y la misma importancia en cuanto al disfrute de los beneficios que genera la actividad estatal". 
los amparos entre distintos procesos de selección, afines en objeto y presupuesto, difieran sin justificación aparente. Por su parte, las compañías de seguros expiden las pólizas con vacíos de conocimiento del riesgo inherente al solicitante, ya que no cuentan con fuentes de información periódicas y por ende actualizadas sobre eventos o inconvenientes contractuales, fuera de lo reportado en el RuP, lo cual ya es un hecho grave.

En el supuesto ideal de contar con información sobre la mayor o menor tendencia al conflicto contractual de los proveedores, muy seguramente cambiarían las condiciones de las aseguradoras para expedir sus pólizas actuando como reguladores eficientes del mercado. Lo anterior, sin que necesariamente las entidades públicas adopten medidas restrictivas a la participación de proponentes interesados en los procesos de contratación. Las empresas entonces se preocuparían más por guardar una imagen positiva de riesgo frente a las compañías de seguros, en el interés no solo de obtener sus garantías en términos competitivos, sino de disminuir la presión comercial derivada de presentarse al mercado con alto riesgo inherente. En consecuencia, la reputación mercantil se convierte en un activo valioso, bajo el supuesto de que manteniendo bajos niveles de riesgo inherente se mejora el atractivo para obtener contratos.

En el escenario actual, incluso luego de que las entidades estatales han remitido al RUP información sobre una multa y/o sanción respecto de un contratista, este no tendrá afectación para suscribir nuevas garantías en nuevos procesos de selección. Las fórmulas de amparos y coberturas serán las mismas para el buen y el mal contratista, sin mayor "blindaje" por parte de las entidades públicas. Lo mismo sucede con la aplicación de la cláusula penal pecuniaria, los índices financieros y otras imposiciones.

El Consejo Nacional de Política Económica y Social (Conpes), mediante documento n. $^{\circ} 3714$ de 2011, denominado "Del riesgo previsible en el marco de la política de contratación pública", indicó las variables de riesgo a considerar por las entidades estatales en Colombia, sin mencionar el riesgo inherente al proveedor de manera particular. Aunque el documento constituye un avance considerable en la articulación de una política pública de tipificación, estimación y asignación de los riesgos previsibles durante la etapa precontractual, se quedó corto, ya que no aporta alguna tipología de riesgo que considere al contratista o su desempeño. El documento clasifica los riesgos como se muestra a continuación:

Riesgos Económicos: Son aquellos que se derivan del comportamiento del mercado, tales como la fluctuación de los precios de los insumos, desabastecimiento y especulación de los mismos.

$[\ldots]$ 
Riesgos Sociales o Políticos: Son aquellos que se derivan por cambios de las políticas gubernamentales que sean probables y previsibles, tales como cambios en la situación política, sistema de gobierno y cambio en las condiciones sociales que tengan impacto en la ejecución del contrato.

\section{$[\ldots]$}

Riesgos Operacionales: Son aquellos riesgos asociados a la operatividad del contrato.

\section{$[\ldots]$}

Riesgos Financieros: Este riesgo tiene dos componentes básicos: el riesgo de consecución de financiación o riesgo de liquidez, y el riesgo de las condiciones financieras.

\section{$[\ldots]$}

Riesgos Regulatorios: Son los posibles cambios regulatorios o reglamentarios que siendo previsibles, afecten el equilibrio contractual.

\section{$[\ldots]$}

Riesgos de la Naturaleza: Son los eventos causados por la naturaleza sin la intervención o voluntad del hombre, que aunque pueden ser previsibles por su frecuencia o diagnóstico están fuera del control de las partes. Para la determinación de su existencia y/o previsibilidad, se podrá acudir a las autoridades públicas o entidades competentes en la recopilación de datos estadísticos o fuentes oficiales.

\section{$[\ldots]$}

Riesgos Ambientales: Se refiere a las obligaciones que emanan de las licencias ambientales, de los planes de manejo ambiental, de las condiciones ambientales o ecológicas exigidas y de la evolución de las tasas retributivas y de uso del agua. Por ejemplo, cuando durante la ejecución del contrato se configuren pasivos ambientales causados por mala gestión de la licencia ambiental y/o el plan de manejo ambiental o el costo de las obligaciones ambientales resulte superior al estimado no siendo imputables a las partes.

\section{$[\ldots]$}

Riesgos Tecnológicos: Se refiere a eventuales fallos en las telecomunicaciones, suspensión de servicios públicos, advenimiento de nuevos desarrollos tecnológicos 
o estándares que deben ser tenidos en cuenta para la ejecución del contrato así como la obsolescencia tecnológica ${ }^{15}$.

Como se observa, todo el tratamiento del riesgo en materia de contratación estatal versa sobre aquel que puede materializarse durante la ejecución del contrato, distinto a que el propio contratista incumpla acorde a sus circunstancias. Los funcionarios públicos a menudo lamentan con preocupación cuando un reconocido mal prestador se convierte en contratista tras un proceso de selección, a sabiendas de que son elevadas las probabilidades de que se presenten inconvenientes.

El supuesto para mitigar la situación anterior sigue siendo la garantía contractual, sin otra o ninguna medida de apoyo agregada. Ahora bien, al momento de presentarse un incumplimiento, por más que la póliza ayude a reducir el daño, siempre existe un margen de afectación económica y social que es irreparable: mayores tiempos de obra, afectación a terceros, sobrecostos, mayores trámites, mayor contaminación, entre otros aspectos que, aun compensados económicamente, no dejan de causar un perjuicio a la sociedad y a la finalidad de la contratación estatal.

Aunado a lo anterior, en el citado documento Conpes, el riesgo contractual es definido desde la posible ocurrencia de un evento y lo que se pueda desprender del mismo, sin considerar la responsabilidad del sujeto (contratista), en los siguientes términos: "El riesgo contractual en general es entendido como todas aquellas circunstancias que pueden presentarse durante el desarrollo o ejecución de un contrato y que pueden alterar el equilibrio financiero del mismo[,] y ha tenido una regulación desde cinco ópticas, asociadas con el proceso de gestión que se requiere en cada caso" ${ }^{16}$.

Esta definición no prevé que el riesgo puede tener orígenes desencadenados por el sujeto en la relación contractual, y tan solo se preocupa por la ruptura del equilibrio económico del contrato. Necesariamente debe considerarse la necesidad de ampliar el concepto de riesgo y tener en cuenta al sujeto y sus características intrínsecas.

Así como existen entidades más proclives a multar o sancionar a sus contratistas, existen prestadores con mayor tendencia a ser sancionados o multados, o bien a tener inconvenientes menores que no les generan multas y/o sanciones efectivas. Habrá que sopesar si existen razones suficientes para adoptar medidas preventivas de mitigación particular y diferenciadas, sin restringir el acceso a la contratación hasta determinados límites.

15 Departamento Nacional de Planeación. Documento conPes n. ${ }^{\circ} 3714$ de 2011, 20-23.

16 Ibíd., 13. 
El ya citado documento Conpes hace referencia a cinco ópticas que menciona y desarrolla la normativa: riesgos previsibles ${ }^{17}$, riesgos cubiertos por las garantías ${ }^{18}$, riesgos imprevisibles ${ }^{19}$, obligaciones contingentes ${ }^{20} \mathrm{y}$ riesgos generales por malas prácticas ${ }^{21}$. La consideración del riesgo inherente al proveedor cabría en los riesgos cubiertos por la garantía única contractual, sin tener en cuenta todas las precisiones ya realizadas sobre las ventajas de contar con información de la conducta y desempeño de los sujetos en el mercado.

Adicionalmente, a pesar de existir unos estándares mínimos para solicitar los amparos de las garantías contractuales al proponente, las determinaciones de los pliegos de condiciones para aplicar uno u otro porcentaje normalmente no están sustentadas en información de mercado, ni en adecuados estándares clasificados, lo cual supone un margen de incertidumbre sobre el fundamento objetivo en el ejercicio de la autonomía de las entidades públicas, asunto que, aunque tratado desde la Ley 80 de 1993, sigue generando confusión en los funcionarios públicos.

A continuación se presenta un ejemplo de cobertura de amparos en varios procesos de obra civil entre 2010 y 2013.

\begin{tabular}{|c|c|c|c|c|c|c|c|c|}
\hline \multirow[b]{2}{*}{ Entidad } & \multirow[b]{2}{*}{$\begin{array}{l}\text { Tipo de } \\
\text { proceso }\end{array}$} & \multirow[b]{2}{*}{ Objeto } & \multirow[b]{2}{*}{$\begin{array}{l}\text { Presupuesto } \\
\text { oficial }\end{array}$} & \multicolumn{4}{|c|}{ Garantía única contractual } & \multirow[b]{2}{*}{ Link } \\
\hline & & & & $\begin{array}{l}\text { Cumpli- } \\
\text { miento }\end{array}$ & Calidad & $\begin{array}{c}\text { Salarios y } \\
\text { prestaciones }\end{array}$ & $\begin{array}{c}\text { Responsabi- } \\
\text { lidad civil }\end{array}$ & \\
\hline $\begin{array}{l}\text { Metroplus } \\
\text { S.A. }\end{array}$ & $\begin{array}{l}\text { Licitación } \\
\text { Nacional } \\
2010\end{array}$ & $\begin{array}{l}\text { Demolición } \\
\text { (obra) }\end{array}$ & $\$ 400.000 .000$ & $20 \%$ & No solicita & $10 \%$ & $20 \%$ & $\begin{array}{l}\text { file://C:User/User/ } \\
\text { Downloads/Estudios\%20 } \\
\text { previos\%20demoliciones. } \\
\text { pdf }\end{array}$ \\
\hline
\end{tabular}

17 Ibíd., 14: "Son todas aquellas circunstancias que de presentarse durante el desarrollo y ejecución del contrato, tienen la potencialidad de alterar el equilibrio financiero del mismo, siempre que sean identificables y cuantificables en condiciones normales".

18 Ibíd., 14 y 15: "Son aquellos relacionados con la seriedad de la oferta, el cumplimiento de las obligaciones contractuales, la responsabilidad extracontractual que pueda surgir para la Administración por las actuaciones, hechos u omisiones de sus contratistas o subcontratistas; y de forma general, los demás riesgos a que se encuentre expuesta la Administración según el tipo de contrato y de acuerdo a lo dispuesto en el artículo 7 de la Ley 1150 de 2007”.

19 Ibíd.,p. 15: "Regula los efectos de tres situaciones que se pueden presentar al ejecutar un contrato: un suceso que se produce después de celebrado el contrato cuya ocurrencia no era previsible al momento de suscribirlo, una situación preexistente al contrato pero que se desconocía por las partes sin culpa de ninguna de ellas, y un suceso previsto, cuyos efectos dañinos para el contrato resultan ser tan diferentes de los planeados, que se vuelve irresistible".

20 Ibíd.: "Son aquellas obligaciones en virtud de las cuales una entidad, estipula contractualmente a favor de su contratista el pago de una suma de dinero, determinada o determinable a partir de factores identificados, por la ocurrencia de un evento futuro e incierto.

21 Ibíd.: "Son aquellos sucesos que pueden ocasionarse por acciones negativas en la contratación o por riesgos operacionales que se manifiestan durante el proceso precontractual y que afectan la ejecución del contrato. Por su proceso de gestión y su relevancia en la contratación colombiana, este tipo de riesgos se abordan en el Manual de las Buenas Prácticas de la Contratación Estatal”. 


\begin{tabular}{|c|c|c|c|c|c|c|c|c|}
\hline \multirow[b]{2}{*}{ Entidad } & \multirow[b]{2}{*}{$\begin{array}{l}\text { Tipo de } \\
\text { proceso }\end{array}$} & \multirow[b]{2}{*}{ Objeto } & \multirow[b]{2}{*}{$\begin{array}{c}\text { Presupuesto } \\
\text { oficial }\end{array}$} & \multicolumn{4}{|c|}{ Garantía única contractual } & \multirow[b]{2}{*}{ Link } \\
\hline & & & & $\begin{array}{l}\text { Cumpli- } \\
\text { miento }\end{array}$ & Calidad & $\begin{array}{c}\text { Salarios y } \\
\text { prestaciones }\end{array}$ & $\begin{array}{c}\text { Responsabi- } \\
\text { lidad civil }\end{array}$ & \\
\hline $\begin{array}{l}\text { Municipio de } \\
\text { Sabaneta }\end{array}$ & $\begin{array}{l}\text { Licitación } \\
\text { pública LP } 08 \\
\text { de } 2013\end{array}$ & $\begin{array}{l}\text { Mtto. vías } \\
\text { (obras) }\end{array}$ & $\$ 446.400 .000$ & $10 \%$ & No solicita & $20 \%$ & $5 \%$ & $\begin{array}{l}\text { http://www.sabaneta. } \\
\text { gov.co/ciudadanos/ } \\
\text { Contratacin/Estudios\% } \\
\text { Previos\%20-LP\%2008- } \\
\text { 2013.pdf }\end{array}$ \\
\hline Metrocali & $\begin{array}{c}\begin{array}{c}\text { Licitación } \\
\text { pública }{ }^{\circ}{ }^{\circ} \mathrm{MC} \\
5.8 .5 .01 .2010\end{array}\end{array}$ & Obra civil & $\$ 84.250 .000 .000$ & $15 \%$ & $10 \%$ & $5 \%$ & $\begin{array}{l}\text { Valor riesgo } \\
\text { asegurado } \\
8 \text { mil } \\
\text { millones }\end{array}$ & $\begin{array}{l}\text { http://www.metrocali. } \\
\text { gov.co/cms/assets/ } \\
\text { descargas/Contratacion/ } \\
\text { MN-5.8.5.01.10/ } \\
\text { PLIEGO-DE-CONDICIONES. } \\
\text { MIO-CABLE.pdf }\end{array}$ \\
\hline $\begin{array}{l}\text { Departamento } \\
\text { de Risaralda }\end{array}$ & $\begin{array}{l}\text { Licitación } \\
\text { pública } \text { n. }^{\circ} \\
\text { SI-OC-01.13 }\end{array}$ & Obra civil & $\$ 499.980 .230$ & $20 \%$ & $20 \%$ & $20 \%$ & 200 SMLMV & $\begin{array}{l}\text { http://www.risaralda. } \\
\text { gov.co/Modulos/ } \\
\text { Contratacion/Archivos } \\
\text { /768ProyectoDePliegosSi- } \\
\text { oc-01-2013.pdf }\end{array}$ \\
\hline
\end{tabular}

Fuente: SECOP - Portal Único de Contratación Pública, https://www.contratos.gov. co/consultas/inicioConsulta.do

En el cuadro se encuentran procesos de selección de diversas entidades públicas. Vale la pena observar que en el amparo de cumplimiento algunas optan por un $20 \%$ del valor total del contrato, otra por el $10 \%$ y otra por el $15 \%$; la garantía de calidad algunas veces se exige, mientras que otras no; el amparo de salarios y prestaciones también tiene porcentajes distintos, y la responsabilidad civil extracontractual algunas veces tiene porcentaje y en otras valor de cobertura.

Del cuadro se constata la carencia de una conducta homogénea sustentada en variables objetivas, lo cual ocurre al amparo de la autonomía de las entidades públicas. En tal sentido, resulta evidente que, aunque pueda existir sustentación, hay un margen de discrecionalidad de tal envergadura que puede fácilmente resultar en arbitrariedad. La cuestión es que se requiere estudios y análisis para la toma de decisiones, esto es, información de mercado como base para seleccionar uno u otro indicador con razones justificadas, y es precisamente en este aspecto donde se advierte el vacío de información de mercado que hoy impera.

IV. MEDIDAS LEGALES ADOPTADAS POR EL SISTEMA ACTUAL PARA IDENTIFICAR A LOS PRESTADORES QUE REPRESENTAN RIESGO PARA LA CONTRATACIÓN ESTATAL

En Colombia las medidas de choque para suprimir el riesgo proveedor se enmarcan en inhabilidades e incompatibilidades consignadas en la Ley $80 \mathrm{de}$ 1993 y la Ley 1474 de 2011. No obstante, estas medidas no tienen un efecto 
concreto en la mitigación del riesgo inherente al proveedor, cuando aquel no ha materializado hechos graves que le limiten legalmente para acceder a la contratación. En otras palabras, el Estado actúa únicamente frente a contratistas que ya han incurrido en incumplimiento contractual.

El artículo $8 .^{\circ}$ de la Ley 80 de 1993 consagra las circunstancias que impiden contratar con un proveedor, siendo de resaltar la prohibición para contratar: durante un tiempo determinado, con personas que hayan sido objeto de caducidad; con quienes se abstengan sin justa causa de suscribir el contrato adjudicado; con quienes hayan sido sancionados disciplinariamente con destitución, y con quienes hayan cometido delitos privativos de la libertad en contra de la Administración Pública, o incurrido en actos de corrupción, entre otras inhabilidades e incompatibilidades.

Conviene comentar las medidas legales que hoy se aplican comúnmente sobre los contratistas, centradas en lo correctivo y punitivo, más no en lo preventivo. Al respecto, la Ley 1474 de 2011 (Estatuto Anticorrupción) establece en el artículo 90 las inhabilidades en casos de multas y/o sanciones, de la siguiente manera:

Artículo 90. Inhabilidad por incumplimiento reiterado. Quedará inhabilitado el contratista que incurra en alguna de las siguientes conductas:

a) Haber sido objeto de imposición de cinco (5) o más multas durante la ejecución de uno o varios contratos, durante una misma vigencia fiscal con una o varias entidades estatales;

b) Haber sido objeto de declaratorias de incumplimiento contractual en por los menos dos (2) contratos durante una misma vigencia fiscal, con una o varias entidades estatales;

c) Haber sido objeto de imposición de dos (2) multas y un (1) incumplimiento durante una misma vigencia fiscal, con una o varias entidades estatales.

La inhabilidad se extenderá por un término de tres (3) años, contados a partir de la inscripción de la última multa o incumplimiento en el Registro Único de Proponentes, de acuerdo con la información remitida por las entidades públicas. La inhabilidad pertinente se hará explícita en el texto del respectivo certificado.

Parágrafo. La inhabilidad a que se refiere el presente artículo se extenderá a los socios de sociedades de personas a las cuales se haya declarado esta inhabilidad, así como [a] las sociedades de personas de las que aquellos formen parte con posterioridad a dicha declaratoria. 
De lo anterior es posible concluir que, bajo el condicionamiento de "la misma vigencia fiscal", un proponente puede ser multado una vez al año sin que tal circunstancia genere acciones punitivas precisas que lo castiguen comercialmente, o que orienten a las entidades públicas a tomar medidas de prevención para mitigar el riesgo que le es inherente al empresario, reflejado, por ejemplo, en amparos o coberturas diferenciales en las garantías. Las entidades públicas suelen realizar descuentos de puntos en las evaluaciones precontractuales de proponentes que se encuentran multados y/o sancionados, debidamente ejecutoriados y reportados en el RuP. Sin embargo, este actuar carece de un referente objetivo y normativo que señale la manera y el impacto del descuento, y que afecte la igualdad para competir, en especial en el evento en que el sancionado cuente con la oferta más ventajosa para la entidad y los fines que esta persigue.

Habrá que tener en cuenta que si bien una única multa al proveedor no puede encasillar su comportamiento habitual, sí es cierto que indica algún factor de riesgo. Cuando una entidad reporta al RuP una multa y/o sanción, cumple con un deber informativo, y las demás toman decisiones particulares y autónomas, incluso poco objetivas, sobre cómo actuar frente a los proveedores que se presentan a los procesos de contratación con algún tipo de multa o sanción.

A su vez, tomar medidas preventivas relacionadas con la valoración de los riesgos inherentes a los sujetos no comporta una desventaja directa para competir por la contratación. El proponente tendría las mismas opciones frente a sus competidores, pero deberá asumir a su costa algunas acciones preventivas de aseguramiento y confianza que mitiguen su riesgo inherente frente al futuro contratante. A esto se añade la necesidad comercial y económica de mejorar, con cada contrato, su evaluación de riesgo y desempeño que, como ya se ilustró, termina siendo una motivación de reputación mercantil y de competitividad.

Lo dicho suscita controversia desde el ámbito del debido proceso y el non bis in idem, ya que podría considerarse la penalidad de restar puntos al proponente como un doble castigo por un mismo hecho, pues se supone que la multa o sanción ejecutoriada significa que el contratista ya respondió por sus actos. Distinto será que aquel antecedente le clasifique en un cierto nivel de riesgo para contratar, sobre el cual deberá acatar ciertos requisitos adicionales.

Las prevenciones para mitigar el riesgo de incumplimiento contractual en los proveedores son tomadas habitualmente por compañías del sector privado, quienes evalúan el desempeño y responsabilidad contractual, e incluso algunas obligaciones no contractuales. La Empresa Colombiana de Petróleos - Ecopetrol, como se precisa más adelante, mantiene dentro de su discrecionalidad de contratación determinaciones de este tipo. 
Si se quiere hacer una evaluación universal del riesgo proveedor en Colombia respecto de los empresarios que contratan con todas las entidades estatales, el marco legal actual ofrece muy poco, ya que se concentra en los riesgos que se puedan presentar durante la ejecución contractual, lo cual es un tema distinto al abordado hasta el momento. Aun así, encontramos alguna referencia en el artículo 6.2 de la Ley 1150 de 2007: "De la información sobre contratos, multas y sanciones a los inscritos. Las entidades estatales enviarán mensualmente a la Cámara de Comercio de su domicilio, la información concerniente a los contratos, su cuantía, cumplimiento, multas y sanciones relacionadas con los contratos que hayan sido adjudicados, los que se encuentren en ejecución y los ejecutados".

Del texto se extrae que las condiciones están dadas para que se habilite por reglamento un estándar de envío de información sobre los contratos terminados o en ejecución a las cámaras de comercio, lo cual daría paso a un sistema de clasificación en el Rup sobre el de desempeño y el nivel de riesgo de incumplimiento contractual de cada contratista a nivel nacional. Esto solo sería posible si existiera cierto grado de universalidad para conocer de manera más panorámica el mercado, puesto que la cobertura actual del RuP es limitada, y la contratación que no tiene ningún tipo de acercamiento al RUP representa un volumen elevado, igual que el número de contratistas que están exentos de inscripción.

Así, entonces, hoy día se cuenta con todas las herramientas tecnológicas $\mathrm{y}$ de registro necesarias y en funcionamiento para generar conocimiento de mercado sobre el riesgo inherente a los proveedores. Solo se requiere la reglamentación política que promueva la adopción de medidas de mitigación del riesgo inherente con los proveedores de manera efectiva.

El beneficio sería para todos los actores: las entidades públicas, por acceder a medidas preventivas particulares y diferenciadas acorde al nivel de riesgo de sus proponentes; las compañías de seguros, por cuanto contarían con información determinante para establecer las condiciones de sus amparos y regular el mercado de alguna manera; los proveedores, quienes buscarían ser más cuidadosos con los recursos públicos, cuidando su reputación y competitividad; y finalmente, la sociedad, como destinataria última y razón de ser de la acción contractual del Estado.

Recuérdese además que la previsiblidad de la contratación pública insta a advertir y planear las circunstancias que rodean la contratación. En palabras de Santofimio:

El contrato del Estado está dominado por la regla general de la previsibilidad, lo que hace que se deba negar el paso a cualquier hipótesis de modalidad negocial aleatoria, no solo por atentatoria contra el interés público en la medida en que pone en peligro el patrimonio de la comunidad, sino en cuanto a que a partir del carácter imperativo de la planeación contractual y de la distribución de riesgos en 
los términos de las leyes 80 de 1993 y 1150 de 2007, prácticamente un contrato del Estado que se caracterice por aleatorio estaría viciado de nulidad absoluta por causa ilícita puesto que desconocería el derecho público de la Nación²2.

La idea es que las entidades puedan identificar factores de riesgo financieros, inconformidades contractuales anteriores (deberes y obligaciones), riesgo de proveedor con medida de reestructuración empresarial, empresa sin trayectoria en el mercado, empresa extranjera nueva en Colombia, entre otras, con la finalidad de aplicar medidas diferenciales de mitigación del riesgo inherente al incumplimiento.

\section{EL CASO ECOPETROL EN COLOMBIA: ESTUDIO DEL HISTORIAL DE DESEMPEÑO CONTRACTUAL PARA LA SELECCIÓN DE CONTRATISTAS}

La entidad pública que cuenta con el sistema de evaluación de proveedores más exigente del Colombia es la estatal petrolera Ecopetrol S.A. ${ }^{23}$. Su régimen de contratación es el aplicable a las empresas industriales y comerciales del Estado, apegadas al derecho privado. La idoneidad de los mecanismos utilizados por esta es materia de otro estudio; el presente tiene el objetivo de analizar cómo la petrolera mitiga el riesgo de contratar con empresas que puedan afectar la finalidad de sus proyectos.

Ecopetrol informa desde su página oficial ${ }^{24}$ que su proceso de selección de contratistas está abierto a la participación de empresas nacionales y extranjeras, siempre y cuando cumplan con los requisitos establecidos para ello. Asimismo, dispone una herramienta para consultar sus proveedores en la que cada uno inscribe su información, algo similar al RuP, denominada SIPROE $^{25}$. Señala expresamente que cuenta con un sistema para evaluar el desempeño de sus contratistas ${ }^{26}$ y que, derivado de ello, existen consecuencias que comportarían ventaja o desventaja comercial frente a la estatal petrolera.

22 SANTOFimio. El carácter conmutativo y por regla general sinalagmático del contrato estatal y sus efectos respecto de la previsibilidad del riego y del mantenimiento de su equilibrio económico, cit., 18.

23 Ecopetrol S.A. es una sociedad de economía mixta, de carácter comercial, organizada bajo la forma de sociedad anónima, del orden nacional, vinculada al Ministerio de Minas y Energía, de conformidad con lo establecido en la Ley 1118 de 2006.

24 Ver: http://www.ecopetrol.com.co/wps/portal/es/ecopetrol-web/ser-contratista/ informacion/ser-contratista-info

25 Sistema de Información de Proveedores Ecopetrol S.A: "es una herramienta de acceso libre y público, dinámica y auto-sostenible que provee a Ecopetrol S.A. de información en línea, de potenciales proveedores de las categorías de bienes y servicios requeridos para su operación". Consulta realizada el 10 de septiembre de 2016 en: https://siproe.ecopetrol.com.co/ slc_selfreg(bD1lcyZjpTUwMA==)/bspwdapplication.do\#vIEW_ANCHOR-ROS_TOP

26 Ecopterol S.A. Procedimiento de despemeño de contratistas. GAB-P-013, versión 2, 2016, 2: "Evaluación de Desempeño del Contratista: Calificación documentada que hace Ecopetrol sobre el cumplimiento de las obligaciones a cargo del Contratista, aplicando los criterios que se hayan 
De esta manera, al contratista incluido en la lista Inconvenientes Gra$v e s^{27}$ queda privado de la oportunidad de participar en concursos cerrados e invitaciones directas. Además, le anticipan que si participa en los concursos abiertos le serán restados puntos. Para ser incluido en la referida lista no basta que el contratista incurra en incumplimientos de aspectos relacionados con las obligaciones contractuales, pues se contemplan, además: aspectos administrativos, referidos a la administración del talento humano; aspectos HSE, concernientes al régimen de accidentes laborales; y aspectos de responsabilidad social empresarial, relacionados con el entorno de la operación, economía local y las obligaciones con sus respectivos contratistas ${ }^{28}$. De esta manera, Ecopetrol brinda algunos elementos clave para la eventual adopción de un sistema de evaluación de desempeño del comportamiento y clasificación en niveles de riesgo de los proveedores. Valga aclarar que para Ecopetrol es claro en que una cosa es el registro con la clasificación y calificación general (como el RUP), y otra muy distinta el desempeño o clasificación de riesgo del proveedor medido por cada contrato.

Lo que interesa en el presente estudio es constatar que la estatal petrolera implementa medidas concretas para mitigar el riesgo inherente a los proveedores proclives al incumplimiento. Nótese que no establece las medidas anunciadas en casos de multas, sanciones o declaratorias de incumplimiento, sino que se refiere a inconvenientes graves. Se interesa por el riesgo que le asiste al sujeto, con independencia de que el mismo se haya materializado anteriormente en multas y/o sanciones, e incluso tiene en cuenta variables contractuales y no contractuales, como los deberes del empresario con sus empleados y el medio ambiente.

A pesar de que la Ley 80 de 1993 establece una serie de inhabilidades e incompatibilidades para participar en la contratación estatal, el tratamiento del riesgo proporcionado por Ecopetrol es de mayor envergadura en la medida en que atiende a los resultados del comportamiento de sus proveedores, tanto en la relación contractual como en aspectos de responsabilidad empresarial del contratista. En consecuencia, el desempeño integral de los aspirantes a la contratación tiene repercusiones comerciales directas sobre el empresario. Ecopetrol toma previsiones para que los inscritos en la lista de inconvenientes graves no lleguen a ser contratistas, sin considerar que puedan suscribir

pactado en el contrato; estará en firme una vez se resuelvan las observaciones del Contratista si las presentare, y sea aprobada y comunicada a éste por el Administrador del contrato".

27 Ibíd.: "Incumplimiento Grave: Incumplimiento que le genera a Ecopetrol y/o a algún integrante del Grupo Ecopetrol, un perjuicio económico, una erogación injustificada, afectación a su imagen o reputación; o aquel incumplimiento que da lugar a Incidentes de Entorno Social y/o Ambientales; o aquel incumplimiento reiterado de algún Criterio de la Evaluación de Desempeño o incumplimiento calificado en este Procedimiento y/u otros documentos aplicables al Contrato, como grave".

28 Ibíd., 4. 
cualquier clase de póliza de seguros con la que se supone queda cubierto el riesgo inherente al proveedor.

Las evaluaciones en Ecopetrol son periódicas y cada determinado tiempo se promedian, ofreciendo la posibilidad de ir mejorando la calificación asignada a los contratistas ${ }^{29}$. Esto presiona y estimula a que los mismos cuiden cada uno de los aspectos particulares y generales de sus contratos, ya que mejorando su calificación de desempeño incrementan las posibilidades comerciales al interior de la misma entidad. No cabe duda de que esto genera un efecto agregado en términos de calidad y cumplimiento.

Una vez dados a conocer los aspectos generales de la evaluación, el procedimiento integra los aspectos cuantitativos de esta por medio de indicadores debidamente parametrizados por rango de cumplimiento (con puntajes totalizados a 100 puntos), recorrido de criterios técnicos, plazos, asuntos administrativos y de talento humano, seguridad industrial, salud ocupacional, medio ambiente, relaciones con el entorno social, mano de obra local y compromisos con terceros ${ }^{30}$.

Es relevante precisar que el diseño de la valoración cuantitativa que propone Ecopetrol con sus indicadores de gestión tiene distintas parametrizaciones en función de la tipología contractual, es decir, encuentra diferencias para evaluar el desempeño de indicadores según la clasificación del contrato suscrito.

El reto para los contratistas, en caso de querer mantener sus opciones para contratar con Ecopetrol, es tener control de sus obligaciones contractuales y de las variables de responsabilidad empresarial en distintos ámbitos de la relación contractual y extracontractual, bajo criterios de mejoramiento continuo que aseguren la supervivencia frente a este gigante comprador de bienes y servicios en Colombia. Esta debería ser la expectativa en toda relación comercial con el Estado: la motivación al mejoramiento continuo, al buen servicio y a la responsabilidad social empresarial. Sin embargo, la realidad actual de las entidades sometidas al Estatuto General de Contratación de la Administración Pública dista considerablemente de este concepto.

Podría pensarse que, en términos de política pública, la idea de evaluar proveedores en toda la contratación nacional mediante múltiples criterios resulta complejo, incluso irrealizable. Por eso la apuesta de presentar a la consideración una clasificación de riesgo para tomar medidas preventivas diferenciadas de mitigación al incumplimiento, sin promover la restricción para participar en procesos licitatorios, y auspiciando la libre competencia. La motivación del empresario por mejorar su competitividad se promueve igualmente cuando de fondo una clasificación en cierto nivel de riesgo le afecte de manera directa su rentabilidad y los amparos de las garantías.

30 Ibíd., 5-11. 
La industria petrolera en Colombia, en su conjunto, se apoya en una entidad para estimar el grado de cumplimiento de las compañías cuando se trata de seguridad industrial y salud ocupacional, el Consejo Colombiano de Seguridad, el cual evalúa la situación y el desempeño de los prestadores respecto de sus responsabilidades en lo indicado. Además, tiene dentro de sus funciones la promoción de la mejora continua de la gestión del riesgo de las empresas que se someten a su escrutinio ${ }^{31}$.

Como producto de las evaluaciones periódicas que realiza el Consejo Colombiano de Seguridad a los contratistas del sector de hidrocarburos, se asigna una puntuación que va de 1 a 100, siendo de señalar que normalmente el sector no tiene en cuenta a contratistas que se encuentran por debajo de 80 puntos, lo cual conmina a los prestadores a ser responsables y cuidadosos en las variables respecto de las cuales saben que serán observados. De esta manera, lo que hace el Consejo Colombiano de Seguridad al expedir su calificación por empresas en el Registro Uniforme de Evaluación a Contratistas (RUC $^{32}$ es informar al sector de hidrocarburos sobre el nivel de responsabilidad y manejo de la gestión del riesgo de los evaluados. La industria petrolera establecerá luego a partir de qué valoraciones admite a los contratistas y qué medidas toma frente a los mismos según su clasificación. En otras palabras, las empresas mitigan a su manera el riesgo inherente al futuro contratista, sin perjuicio de las garantías que exijan.

Se considera que el referido sistema constituye, más que un obstáculo, una motivación para los empresarios, quienes, al lograr una calificación o clasificación positiva de su riesgo inherente, legitiman su capacidad, responsabilidad y cumplimiento para contratar con las empresas del sector de hidrocarburos. Así lo concibe el Consejo Colombiano de Seguridad al decir: "El RUC ${ }^{\circledR}$ logró consolidar la gestión del riesgo como una ventaja competitiva, generando más oportunidades al ampliar la participación en el mercado de las empresas actualmente inscritas a través de la adjudicación de nuevos

31 El Consejo Colombiano de Seguridad (CCS) es una asociación tipo empresarial y profesional sin ánimo de lucro, con personería jurídica propia, que contempla en su objeto social la ejecución de actividades científicas y tecnológicas, las cuales se ven representadas de manera puntual en servicios científico tecnológicos ( $\mathrm{SCT}$ ) dirigidos hacia la promoción, divulgación, adaptación, aplicación y puesta en funcionamiento de tecnologías relevantes para varios sectores productivos en actividades específicas de seguridad industrial, salud ocupacional y protección ambiental. Consulta realizada el 25 de septiembre de 2016 en: http://ccs.org.co/interna_general. php?idcategoria $=8 \&$ idnoticia $=109$

32 El Registro Uniforme de Evaluación del Sistema de Gestión en Seguridad, Salud Ocupacional y Ambiente - SSOA para Contratistas - RUC $^{\circledR}$ es la herramienta de evaluación del desempeño en SSOA, aplicada en empresas contratistas del sector hidrocarburos y de otros sectores contratantes, con el objetivo principal de impulsar el desempeño y la mejora continua en la gestión del riesgo y el cumplimiento de los aspectos legales y de otra índole. Consulta realizada el 25 de septiembre de 2016 en: http://ccs.org.co/interna_ruc.php?idnoticia=77\&idcategoria=15 
contratos, optimización de procesos, reconocimiento en otros sectores de la industria, entre otros" ${ }^{\prime 3}$.

Es pertinente precisar que no se pretende defender la idea de que las empresas colombianas que quieran contratar con el Estado deban obtener certificaciones internacionales o someterse a mayores trámites o engorrosos procedimientos para obtener puntaje en los procesos de selección ${ }^{34}$; lo que hemos expuesto es la necesidad de conocer el riesgo inherente de las personas naturales y jurídicas para que el Estado se proteja del riesgo de incumplimiento con las medidas adecuadas acorde a la situación clasificada de los proveedores.

\section{MODELOS INTERNACIONALES DE EVALUACIÓN DEL DESEMPEÑO PARA MITIGAR EL RIESGO INHERENTE AL PROVEEDOR}

Numerosas empresas del sector privado a nivel internacional han encontrado en la evaluación del desempeño de sus proveedores una fuente importante para mitigar los riesgos de incumplimiento inherentes a la conducta de los contratistas, actuación que resulta pertinente por ser preventiva, sin perjuicio de las garantías contractuales que se puedan solicitar.

Es así como empresas de amplio reconocimiento internacional, como Dupont, Pemex, Pacific Rubiales, y tantos otros ejemplos del sector de hidrocarburos y servicios públicos, administran sistemas para el registro con clasificación y calificación, así como evaluación del desempeño de los proveedores. En términos generales, el asunto es similar a como lo aborda Ecopetrol. Lo que genera preocupación es el riesgo inherente al proveedor, concepto que se acuña en este escrito.

A nivel de contratación pública en España, la creación de la Oficina Nacional de Evaluación (ONE), facultada para tomar medidas preventivas a nivel financiero sobre contratos de concesión obra y servicios públicos, constituye una garantía para la eficacia y la sostenibilidad de las inversiones públicas. Si bien la necesidad de fortalecer el sistema encuentra eco en la academia, en la práctica la evidencia es fehaciente. En palabras de Lazo Vitoria:

Hace tiempo que se viene insistiendo en la necesidad de reforzar el sistema de controles sobre la contratación pública. No se trata de una mera preocupación teórica o de corte academicista sino que derivada de la constatación práctica (evidencia hay de sobra) de que este particular ámbito de actuación -extenso y

33 Ibíd.

34 La Ley 1150 de 2007 eliminó la exigencia de certificaciones internacionales, justamente porque terminaban favoreciendo a determinadas compañías, sin que fuera un asunto de igualdad material en el mercado. 
muy complejo- es un "área de riesgo" y que, por lo tanto, requiere de una atención preferente mediante la articulación de afinados mecanismos de vigilancia ${ }^{35}$.

No obstante, el espectro de actuación de la onE se encuentra limitado a los contratos de concesión de obra y servicios públicos, escapando al control preventivo una importante porción de la tipología contractual de la Administración y mecanismos de colaboración público-privada ${ }^{36}$.

Si bien en Colombia se ha dado un paso relevante para analizar el mercado de lo público y sus riesgos mediante la creación de Colombia Compra Eficiente, a través de la cual se construyen en la actualidad mecanismos orientadores y estándares para lograr en la práctica una mayor seguridad en la contratación pública, todavía existe la necesidad de implementar medidas que potencien un mayor control preventivo respecto a la posible contratación fallida.

En lo que respecta a la contratación pública en Chile, el tratamiento del riesgo inherente a sus proveedores se integra desde el marco constitucional. El equivalente chileno a la Ley 80 colombiana es la Ley 19.886 del 29 de agosto de 2003, Ley de Compras Públicas ${ }^{37}$, la cual sirve de base a los contratos administrativos de suministro y prestación de servicios. Salta a la vista que, en materia de principios rectores, solo se mencionan los de transparencia, eficiencia e igualdad de competencia; y que, por virtud de su expedición, se crearon simultáneamente la Dirección de Compras y Contratación Pública ${ }^{38}$,

35 Lazo Vitoria, X. La Oficina Nacional de Evaluación: un control reforzado para las licitaciones públicas de la Administración General del Estado y de las Entidades locales. En Observatorio Contratación Pública. Consultado el 29 de agosto de 2016 en: http://www.obcp. es/index.php/mod.opiniones/mem.detalle/id.214/relcategoria.208/relmenu.3/chk.37351ec9ddc $005 \mathrm{~b} 73 \mathrm{e} 5 \mathrm{a} 5 \mathrm{a} 5086265 \mathrm{e} 28$

36 Ibíd.

37 La Ley 19.886 del 29 de agosto de 2003 entró en vigencia el 24 de octubre de 2004, mediante Decreto Supremo 250.

38 Ministerio de Hacienda, Gobierno de Chile, Dirección de Compras y Contratación Pública. Cartilla Ley n. ${ }^{\circ} 19.886$ de Compras Públicas y Reglamento, 2003, p. 10. Entre sus funciones: “(i) Asesora a los organismos públicos en la planificación y gestión de sus procesos de compras y contrataciones; (ii) Administra el Sistema de Compras Públicas y demás sistemas necesarios para el desarrollo de un mercado electrónico eficiente, que garantice una óptima gestión de abastecimiento y óptimos niveles de competencia; (iii) Es responsable de la creación, administración y actualización constante de ChileProveedores, el Registro Electrónico Oficial de Proveedores del Estado, que permite a los proveedores presentar centralizadamente toda su documentación. Se generan así grandes ahorros de tiempo, papel y fotocopias, ya que todo está disponible en formato digital; (iv) Promueve la máxima competencia entre los proveedores de la Administración Pública; (v) Garantiza que los organismos públicos accedan a la información sobre proveedores de mejor calidad y en menores tiempos (vi) Establece las políticas y condiciones de uso de los sistemas de información y contratación electrónicos o digitales que se mantengan disponibles". Consulta realizada el 10 de agosto de 2016 en: http://www.dgmn.cl/ transparencia/leyes_dgmn/Doc.LEGALEs/Ley\%2019.886\%20Compras\%20P\%C3\%BAblicas\%20 y\%20Reglamento.pdf 
el Tribunal de Contratación Pública ${ }^{39}$ y el Sistema Electrónico de Compras y Contratación Pública ${ }^{40}$.

Haciendo un paralelo con Colombia, el homólogo a la Dirección de Compras y Contratación Pública de Chile sería Colombia Compra Eficiente; el tribunal sería nuestro Consejo de Estado; y el sistema electrónico para darle visibilidad a la contratación sería el Sistema Electrónico de Contratación Pública (SECOP). Como en Colombia, la ley chilena de contratación cubre con su régimen a la mayor parte de entidades públicas y exceptúa: empresas de servicios públicos; entidades que por norma expresa contemplen regímenes excepcionales, y aquellas que por su naturaleza requieran que su contratación sea secreta o reservada. Concluimos que, en principio, contamos con organismos homólogos.

En Chile la entidad encargada de administrar el registro de proveedores, el Rup de Colombia, es la mencionada Dirección de Compras y Contratación Pública. El objetivo primordial de la herramienta es compilar toda la documentación de los proveedores de manera centralizada, y que la misma esté disponible en formato digital para mayor facilidad de manejo y eficiencia, con un valor agregado: "garantiza que los organismos públicos accedan a la información sobre proveedores de mejor calidad en menores tiempos" ${ }^{\prime 4}$. Básicamente, el sistema es una operación similar a la realizada por el SECOP en Colombia, dado que su orden es presentar los negocios y los términos de referencia para la consulta pública, de manera tal que los proponentes puedan participar en igualdad de condiciones y hacer sus ofrecimientos. La gran diferencia es que en Chile los proponentes no tienen que usar papel para presentar sus ofrecimientos, sino que todo lo hacen a través del sistema electrónico (salvo excepciones), donde además se unifica la documentación de los empresarios.

La mencionada norma, además de ocuparse de las definiciones contractuales y los procedimientos respectivos, aborda el tema de las garantías como parte de la mitigación del riesgo proveedor y da lugar a la inclusión de cláusulas exorbitantes al derecho común. Comoquiera que el objetivo es llegar al tema del seguimiento o evaluación de desempeño que permita evidenciar el tratamiento del riesgo inherente al proveedor (o concepto similar) en Chile, se introduce el capítulo 85 del Reglamento de la Ley $19.886^{[42]}$, titulado "De la evaluación de proveedores", en donde se aborda el desempeño de proveedores:

39 Ibíd., 11: "Garantiza transparencia e igualdad: ante éste, cualquier empresa puede reclamar de los actos u omisiones ilegales o arbitrarios que lo afecten durante los procesos de licitación".

40 Ibíd.: "Sistema Electrónico de Información, de acceso público y gratuito, administrado por la Dirección de Compras y Contratación Pública".

41 Ibíd., 10.

42 Se aclara que mientras que en Colombia se reglamentan y modifican tales asuntos vía decreto, en Chile se hace lo propio mediante reglamento, indicando qué ley se reglamenta. 
El proceso de evaluación tendrá por objeto determinar si concurre alguna causal de inhabilidad o incompatibilidad para contratar con las Entidades. Además, tendrá por objeto acreditar la veracidad de los antecedentes, la situación legal y la situación financiera de los postulantes a proveedores inscritos.

El proceso de evaluación de los postulantes a proveedores inscritos podrá ser efectuado directamente por la Dirección o podrá ser encomendado a terceros para que éstos recaben la información necesaria y efectúen la evaluación.

La evaluación se traducirá en informes estandarizados que permitan evaluar a cada postulante proveedor inscrito. La evaluación de los postulantes a Proveedor deberá contar con un procedimiento claro y transparente que asegure la confidencialidad de los antecedentes aportados y la objetividad y celeridad del proceso evaluatorio ${ }^{43}$.

De lo anterior resulta equivalente con Colombia el manejo del registro de información, el cual obedece a contratos y antecedentes jurídicos y financieros; mientras que se identifican como diferencias: i) la potestad del Gobierno Central para autorizar la contratación de terceros para verificar la veracidad de los antecedentes, asunto que en Colombia es discrecional de la entidad que desata el proceso de contratación, y ii) que en Chile sea centralizada la verificación de autenticidad, mientras que en Colombia la cámara de comercio no asume tal compromiso sino que parte de la buena fe y efectúa las acciones pertinentes de clasificación y calificación.

Se podría insinuar que los procesos para determinar el riesgo inherente al proveedor son prácticamente idénticos en Colombia y Chile, contando este último con un paso adicional respecto de la revisión de los antecedentes consignados por las personas naturales y jurídicas que pretenden contratar con el Estado, acción que puede revelar información importante para tomar medidas frente a ciertos actores. Sin embargo, el monitoreo de la conducta de los proveedores para fines de evaluar periódicamente el nivel de riesgo inherente que se relaciona con el nombre comercial no se aborda a cabalidad como en el caso de las empresas privadas o estatales que compiten abiertamente en el mercado.

\section{CONCLUSIONES}

En la actualidad el Estado colombiano carece de una metodología en el Estatuto de Contratación Estatal para el monitoreo del desempeño de sus proveedores y la clasificación del riesgo inherente al incumplimiento contractual que puedan presentar, sin perjuicio de la información de multas y sanciones que las entidades públicas deben remitir a la cámara de comercio 
para constancia en el Registro Único de Proponentes. Este escenario dificulta la toma de medidas preventivas para proteger los objetivos de las contrataciones y el patrimonio público.

La contratación pública en Colombia requiere contar con registros objetivados y parametrizados de información significativa del mercado que puedan arrojar indicadores de riesgo inherente al proveedor, bajo criterios de desempeño, calidad, tiempo de experiencia, historial contractual y, en general, las variables que permitan tomar medidas de mitigación por el riesgo de incumplimiento que le es propio al sujeto que pretende ofrecer productos y servicios al Estado. Se precisa, además, que el registro debe ser centralizado y universal, cubriendo el amplio espectro de tipologías contractuales que ofrece la Administración.

Se ha señalado como un inconveniente en la práctica contractual de las entidades públicas el hecho de que, aun remitiendo al RuP una multa o sanción sobre un contratista, este no tendrá afectación alguna en cuanto a las garantías futuras que pretenda adquirir como adjudicatario en nuevos procesos de selección, fuera de las inhabilidades e incompatibilidades legales para contratar, puesto que las garantías y exigencias requeridas en los procesos de selección serán las mismas para el buen y para el mal contratista, sin mayor "blindaje" por parte de las entidades públicas. Esta circunstancia resulta contraria al espíritu de mejoramiento continuo, buen servicio y responsabilidad social que debe irradiar la contratación pública.

Como se ha reiterado en el presente escrito, en Colombia las medidas para evitar el riesgo inherente al proveedor se limitan a inhabilidades consagradas en la Ley 80 de 1993 y la Ley 1474 de 2011. No obstante, dichas medidas no tienen aplicación para generar acciones o medidas de mitigación del riesgo cuando el contratista no ha caído en la materialización de hechos graves. Por consiguiente, se ha hecho énfasis en la necesidad de observar el comportamiento de los proveedores disponibles e interesados en contratar, o que han contratado con el Estado, para identificar su riesgo inherente de incumplimiento y tomar las medidas preventivas correspondientes.

El caso de Ecopetrol es un punto de referencia valioso para el análisis y registro de resultados del comportamiento de proveedores, tanto en la relación contractual como en aspectos de responsabilidad empresarial del contratista. Para Ecopetrol el desempeño histórico contractual tiene repercusiones directas a la hora de tratar de acceder a la contratación, por cuanto el registro de antecedentes cuestionables conduce a la exclusión del proceso contractual, sin importar la eventual suscripción de una póliza de seguro que pretenda cubrir el riesgo inherente al proveedor.

Este escrito señala la importancia de las medidas para mitigar el riesgo de contratación con prestadores proclives a inconvenientes o incumplimientos contractuales, sin que las acciones resten competitividad, como es el conocido 
descuento de puntos en las evaluaciones de las propuestas por causa de multas o sanciones, ya que puede el afectado contar con la oferta más ventajosa para la entidad y los fines que esta persigue. En tal sentido, se considera que tomar medidas preventivas, acorde a la clasificación de riesgos, no implica desventaja directa para contratar, sino un castigo cautelar y proporcionado, que seguramente implicará cargas para los afectados, pero no restringe la contratación.

No defendemos que las entidades públicas asuman incumplimientos contractuales de proveedores sin el debido proceso; aspiramos más bien a que puedan identificar - a priori-factores de riesgo financieros, y a que dispongan del historial de inconformidades contractuales y de información sobre la experiencia en determinado mercado y sobre la calidad en la ejecución de obras o prestación de servicios, entre otros, que permitan adoptar medidas diferenciales de mitigación del riesgo inherente de incumplimiento, optimizando con ello de los recursos públicos invertidos en la contratación pública.

La inclusión del riesgo inherente al proveedor como criterio preventivo en la contratación pública es perfectamente factible. Existen los recursos tecnológicos, el sustento normativo y el funcionamiento organizacional necesarios para generar el conocimiento de mercado que soporte su incorporación en el esquema de riesgos a considerar por las entidades públicas en sus procesos de contratación pública.

\section{REFERENCIAS}

BASU, K. (2011). Más allá de la mano invisible. Fundamentos para una nueva economía. México: FCE.

Bernal Pedomo, J. y Molina Bentacur, C. (2016). Derecho administrativo. 14. a ed. Bogotá: Legis.

Benavides, J. L. (2004). El contrato estatal. Entre el derecho público y el derecho privado.

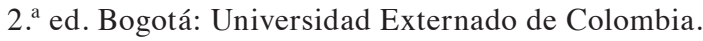

Departamento de Nacional de Planeación (2011). Documento conPes (Consejo Nacional de Política Económica y Social) n. ${ }^{\circ}$ 3714. Del riesgo previsible en el marco de la política de contratación pública.

Gobierno de Chile, Ministerio de Hacienda, Dirección de Compras y Contratación Pública. Cartilla de la Ley n. ${ }^{\circ} 19.886$ de 2003 y su Reglamento. Consulta realizada el 10 de agosto de 2016 en: http://www.dgmn.cl/transparencia/leyes_dgmn/DOC.LEGALES/Ley\%20 $19.886 \% 20$ Compras\%20P\%C3\%BAblicas\%20y\%20Reglamento.pdf

Ecopetrol S.A. Procedimiento de desempeño de contratistas, GAB-P-013, 2016, versión 2.

Gobierno de Colombia, Colombia Compra Eficiente. Guía de Garantías en Procesos de Contratación. 
Gobierno de Colombia, Colombia Compra Eficiente. Guía para la Elaboración de Estudios de Sector.

Gobierno de Colombia, Colombia Compra Eficiente. Manual para la Identificación y Cobertura del Riesgo en los Procesos de Contratación.

Hernández Silva, A. (2008). La responsabilidad contractual del Estado: ¿una responsabilidad sin imputación? Revista de Derecho Privado, Universidad Externado de Colombia, n. ${ }^{\circ}$ 14, 171-191.

Lazo Vitoria, X. (2016). La Oficina Nacional de Evaluación: un control reforzado para las licitaciones públicas de la Administración General del Estado y de las Entidades locales. Observatorio Contratación Pública. Consultado el 12 de agosto de 2016 en: http://www.obcp.es/index.php/mod.opiniones/mem.detalle/id.214/relcategoria.208/ relmenu.3/chk.37351ec9ddc005b73e5a5a5086265e28

Mierr Barrosa, P. (2010). Los riesgos, su identificación, asignación y amortización en los contratos del Estado. Revista de Ingeniería, Universidad de los Andes, n. 32 (juliodiciembre), 95-107.

República de Colombia, Ley 80 de 1993, "por la cual se expide el Estatuto General de Contratación de la Administración Pública".

República de Colombia, Ley 1150 de 2007, "por medio de la cual se introducen medidas para la eficiencia y la transparencia en la Ley 80 de 1993 y se dictan otras disposiciones generales sobre la contratación con Recursos Público".

República de Colombia, Ley 1474 de 2011, "por la cual se dictan normas orientadas a fortalecer los mecanismos de prevención, investigación y sanción de actos de corrupción y la efectividad del control de la gestión pública".

Safar Díaz, M. S. (2009). Análisis económico de los procedimientos de selección de contratistas del Estado en el Derecho colombiano: hacia un mecanismos eficiente y transparente. Serie de Derecho Administrativo n. ${ }^{\circ}$ 6. Bogotá: Universidad Externado de Colombia.

SAntofimio, J. O. (2009). El carácter conmutativo y por regla general sinalagmático del contrato estatal y sus efectos respecto de la previsibilidad del riego y del mantenimiento de su equilibrio económico. Revista Digital de Derecho Administrativo, Universidad Externado de Colombia, n. ${ }^{\circ}$ 1, 1-58.

SuÁrez Beltrán, G. (2009). La nueva contratación pública en Colombia. Anotaciones sobre la Ley 1150 de 2007 y sus decretos reglamentarios. Bogotá: Legis.

SuÁrez Beltrán, G. (2014). Estudios de derecho contractual público. 4. a ed. Bogotá: Legis. 